Relato de Experiência

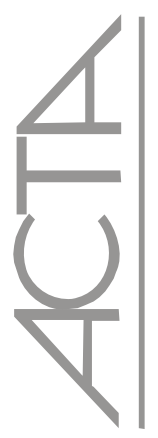

\title{
A capacitação de enfermeiros para a assistência domiciliar: uma abordagem psicossocial
}

\author{
Preparing nurses to provide quality home care: a psychosocial approach \\ La capacitación de los enfermeros para la asistencia domiciliaria: un abordaje psicosocial \\ Vilanice de Araújo Alves Püschel ${ }^{1}$, Cilene Aparecida Costardi
}

\section{RESUMO}

Este trabalho tem por objetivo relatar a experiência da realização de um curso de capacitação para a assistência domiciliar na abordagem psicossocial. O curso foi oferecido para sete profissionais com experiência na área. É apresentado o referencial teórico e a metodologia empregada no curso, assim como os resultados das três partes que constituíram o programa de capacitação: a do reconhecimento dos sujeitos e da mobilização afetiva; a da mobilização de conceitos e das representações das práticas profissionais; a da aplicabilidade do modelo psicossocial no domicílio.

Descritores: Educação em enfermagem; Capacitação de recursos humanos em saúde; Assistência domiciliar

\begin{abstract}
The objective of this paper is to describe a psychosocial approach in the development and implementation of a course to prepare health care professionals to provide quality home care. This course was implemented among seven health care professionals working in home care. This paper discusses the conceptual framework and methodological underpinning for the development and implementation of the course. In addition, this paper discusses the following phases of implementation of the course: recognition of the subjects and affective mobilization, conceptualization and meaning of professional practice, and applicability of the psychosocial model in home care.
\end{abstract}

Keywords: Education, nursing; Health human resource training; Home nursing

\section{RESUMEN}

Este trabajo tiene por objetivo relatar la experiencia de la realización de un curso de capacitación para la asistencia domiciliaria en el abordaje psicosocial. El curso fue ofrecido para siete profesionales con experiencia en el área. Se presenta el referencial teórico y la metodología empleada en el curso, así como los resultados de las tres partes que constituyeron el programa de capacitación: el reconocimiento de los sujetos y de la mobilización afectiva; la mobilización de conceptos y las representaciones de las prácticas profesionales; la aplicabilidad del modelo psicosocial en el domicilio.

Descriptores: Educación en enfermería; Capacitación de recursos humanos en salud; Atención domiciliaria de salud

\footnotetext{
${ }^{1}$ Professora Doutora do Departamento de Enfermagem Médico-Cirúrgica da Escola de Enfermagem da Universidade de São Paulo - USP - São Paulo (SP), Brasil.

${ }^{2}$ Professor Titular do Departamento de Enfermagem Médico-Cirúrgica da Escola de Enfermagem da Universidade de São Paulo - USP - São Paulo (SP), Brasil.
} 


\section{INTRODUÇÃO}

No Brasil, a assistência domiciliar (AD) na forma como se delineia na atualidade é uma prática recente. Em 2002, uma pesquisa ${ }^{(1-2)}$ mostrou que a assistência prestada no domicílio se baseava no modelo clínico e hospitalar e privilegiava o atendimento do corpo doente, fracionado pelos diferentes profissionais que prestavam uma atenção voltada, principalmente, para a realização de procedimentos técnicos. Evidenciava-se, assim, um vazio teórico-instrumental a exigir novos investimentos de capacitação, considerando essa realidade de prática que tem, no interjogo das relações familiares, o seu núcleo constituído.

Neste sentido, se justificou a construção de um programa de capacitação multiprofissional, apresentado neste trabalho que tem como objetivo relatar a experiência da realização de um curso de capacitação de enfermeiros para a assistência domiciliar na abordagem psicossocial ${ }^{(3)}$.

\section{A CAPACITAÇÃO DE ENFERMEIROS PARA A ASSISTENCIA DOMICILIAR NA ABORDAGEM PSICOSSOCIAL}

Algumas autoras ${ }^{(4)}$ vêem com preocupação a possibilidade de se levar para o lar da pessoa o modelo de assistência institucional, uma vez que o contexto é diferente, assim como as demandas por cuidados. Apontam, como limitações quanto ao cuidado de enfermagem, a escassez de programas de capacitação dos enfermeiros e técnicos de enfermagem voltados para a AD.

Assim, acredita-se que a capacitação baseada no modelo hospitalar não atende aos propósitos da $\mathrm{AD}$. Com base neste pressuposto, foi criado e ministrado um curso de capacitação para a assistência domiciliar numa abordagem psicossocial, utilizando-se como estratégia pedagógica a mobilização de conceitos* dos participantes ${ }^{(3)}$.

O investimento dessa capacitação consistiu em trazer, para as participantes do curso, a distinção entre dois modelos (o clínico e o psicossocial), de modo a explicitar os referenciais teórico-metodológicos que vinham sustentando a $\mathrm{AD}$, que privilegiava o modelo clínico ainda que em cenário diferenciado.

* Utiliza-se o termo mobilização de conceitos, por considerar que ao iniciar o curso de capacitação as participantes tinham um conceito de assistência domiciliar e era neste que se amparava para prestar a assistência no domicilio. Para verificar se houve a assimilação do referencial da abordagem psicossocial ministrada no curso, levou-se em consideração os preceitos de Vygotsky. Para esse autor, na verdadeira formação de conceitos, é igualmente importante unir e separar, e a sintese deve combinar com a análise, ou seja, gerar um conceito. Este só aparece quando os traços abstraídos são sintetizados novamente e a sintese abstrata dai resultante torna-se o principal instrumento do pensamento (Vigotski LS. Pensamento e linguagem. São Paulo: Martins Fontes; 1998).
Uma das formas utilizadas para apreender as modificações nos sistemas de conceitos e nos esquemas de ação dessas participantes foi que elas respondessem às seguintes perguntas (no primeiro e último dia do curso): o que você entende por assistência no domicílio, o que você entende por abordagem à família na assistência domiciliar e o que você entende por abordagem ao paciente inserido nesse contexto.

Para se implementar o curso, havia a necessidade de construir o referencial teórico para guiar o desenvolvimento de tal curso. Este se baseou no modelo psicossocial de atenção ao indivíduo e à família na $\mathrm{AD}^{(3,5)}$, organizado pelas autoras. O pressuposto para a opção pela abordagem psicossocial é o de que ela possibilita ampliar o olhar sobre a dinâmica do indivíduo e da família, utilizando-se da relação empática e da construção de vínculos, como condição para a participação conjunta (profissionais, pessoa doente e família) na escolha dos problemas a serem trabalhados para a melhor recuperação possível e, desta forma, poder responder mais adequadamente às demandas advindas de um atendimento domiciliar. No curso, procurou-se difundir os novos conceitos do modelo psicossocial, assim como instrumentalizar o grupo a aplicá-los. Para isso, levou-se em consideração o que as participantes já sabiam e, após o curso, identificar se houve aprendizagem efetiva dos conteúdos trabalhados no decorrer do referido curso.

Adotou-se, como estratégica metodológica, as seguintes etapas: a formação do grupo; a estruturação do conteúdo, com base pedagógica construtivista; a definição de estratégias, apoiadas em dinâmicas de grupo; o levantamento dos conceitos relativos ao tema a partir de depoimentos das participantes, e a análise dos depoimentos.

A base construtivista foi o fio condutor do curso de capacitação profissional para a assistência domiciliar que foi ministrado na Escola de Enfermagem da Universidade de São Paulo, após o Projeto de Pesquisa ter sido aprovado pelo Comitê de Ética da Escola**. Teve duração de trinta horas e foi aberto aos profissionais de saúde de nível superior, com experiência na área de $\mathrm{AD}$, que tiveram interesse e disponibilidade de tempo para participação.

Eleger o construtivismo, como referência para o programa de capacitação em questão, pressupôs considerar que o indivíduo "não é mero produto do ambiente nem um simples resultado de suas disposições internas, mas, sim, uma construção própria (...). Em equivalência, o conhecimento não é cópia da realidade, mas sim uma construção do ser humano" ${ }^{(6)}$.

\footnotetext{
${ }^{* *}$ Este relato de experiência constitui-se uma parte da pesquisa desenvolvida por Püschel(3), que utilizon o curso de capacitação como estratégia metodológica dessa pesquisa.
} 
A organização dos conteúdos do curso permitiu avançar no sentido de trazer os princípios construtivistas atrelados aos princípios e às estratégias da abordagem psicossocial, de modo a valorizar a pessoa participante, sua história, sua capacidade de ver e reconstruir as pontes de conteúdos, para ressignificar conceitos e práticas.

No curso, foram aplicadas estratégias que possibilitassem às participantes sentirem-se num ambiente agradável, mais relaxado, capaz de favorecer a mobilização de seus conceitos e que proporcionasse maior possibilidade de abertura ao novo. Para isso, foram utilizados métodos psicodramáticos.

A seguir são mostrados resumidamente os resultados referentes às três partes que constituíram o programa de capacitação: a do reconhecimento dos participantes e da mobilização afetiva; a da mobilização de conceitos e das representações da prática; a da aplicabilidade do modelo psicossocial, por meio da consulta profissional.

\section{RESULTADOS OBTIDOS COM A REALIZAÇÃO DO CURSO DE CAPACITAÇÃO PARA A ASSISTÊNCIA DOMICILIAR}

O reconhecimento dos participantes e a mobilização afetiva

Sete profissionais que atuavam na AD fizeram o curso de capacitação, sendo seis enfermeiras e uma psicóloga. Foram realizados seis encontros, sendo que os dois primeiros foram importantes para promover a integração grupal por meio do uso de jogos psicodramáticos, sendo utilizada a Dinâmica do Barbante para a apresentação pessoal e levantamento de expectativas do curso e o Jogo das Bolinhas, o que permitiu fazer a integração, reconhecer as pessoas no grupo, favorecer o relacionamento interpessoal e introduzir a proposta do curso que consistia na abordagem psicossocial. Foram utilizadas Dinâmicas de Dramatização das Práticas de Referência para identificar as situações vivenciadas na assistência domiciliar que seriam trabalhadas durante o curso. Para a avaliação do curso de forma individual e grupal, usou-se a Dinâmica do Mercado de Troca e a Dinâmica do Jornal.

Assim, encontrou-se no psicodrama aquilo que precisava para trabalhar afetivamente o grupo de participantes. O resultado foi compensador, pois foi facilitador do processo ensino-aprendizagem.

A mobilização de conceitos e das representações da prática profissional

Foram analisados os conceitos elaborados pelas participantes no início e ao término do curso a respeito de assistência domiciliar, de abordagem à família e ao indivíduo.

Nos conceitos apresentados no início e comparados aos do final do curso verificou-se que houve incorporação do referencial teórico abordado no curso de capacitação, uma vez que os conceitos mostrados no final tinham um novo sentido e novos elementos constitutivos, além de terem sido consideradas algumas habilidades para a abordagem psicossocial no que se relaciona à consideração do contexto, da dinâmica familiar, da parceria nas condutas (pessoa doente/família/profissional) e da busca da melhor resposta possível à intervenção proposta e conjuntamente acordada. Isso demonstra que a intervenção pedagógica foi uma estratégia importante e decisiva para se atingir o propósito do curso.

Situações vivenciadas no domicílio foram apresentadas e discutidas no decorrer do curso, com o olhar da abordagem psicossocial. Verificou-se que as participantes tinham dificuldades para identificar os problemas principais dessas experiências, que se relacionavam à questão da relação humana e os seus conflitos, trama de sentidos que sustenta a dinâmica familiar, sendo o profissional incompetente para uma abordagem mais integral o que, possivelmente, o levava a direcionar a prática voltada para a realização de procedimentos técnicos.

\section{A aplicabilidade do modelo psicossocial no domicílio}

Uma forma também utilizada para avaliar a estratégia do curso consistiu na aplicação, pelas participantes, de um Instrumento de Abordagem Psicossocial aos indivíduos e famílias que recebiam a assistência domiciliar, durante a consulta profissional ${ }^{(7)}$. Buscou-se, com essa estratégia, verificar o quanto as participantes haviam assimilado o conteúdo da abordagem psicossocial desenvolvido no curso.

Após essa aplicação, foram analisados os conteúdos dos instrumentos preenchidos, assim como foram discutidas com as participantes as experiências da realização da consulta na abordagem psicossocial. Verificou-se que, embora tenham ampliado a abordagem do indivíduo e da família para além da fisiopatologia, ainda ficou evidente a dificuldade, tanto para a elaboração de raciocínio psicossocial ${ }^{(7)}$ quanto para a proposição de intervenções psicossociais.

Não houve nas consultas realizadas pelas profissionais de $\mathrm{AD}$, expressões de questionamentos, no sentido de apurar a compreensão, recompor a avaliação, articular informações, apresentar hipóteses. Os julgamentos e as condutas ficaram restritos aos preceitos técnicos, levando em consideração algumas opções preferenciais. Assim, a primeira barreira, ou seja, a ampliação do foco de forma a perceber e envolver o conjunto (pessoa doente, familiar, profissional) na avaliação e tomada de decisão, parece ter sido uma etapa incorporada aos conceitos e ações profissionais, porém o raciocínio psicossocial não se 
constituiu, evidenciando um descompasso entre os referenciais e sua primeira expressão operacional ${ }^{(7)}$. Tal situação mostra que os participantes, embora tenham assimilado novos conteúdos durante a realização do curso, esses ainda não foram incorporados à prática profissional, o que exige novos investimentos para a capacitação profissional.

\section{CONSIDERAÇÕES FINAIS}

Oferecer o curso de capacitação para profissionais de saúde, especialmente para enfermeiros, foi um grande aprendizado. Os dados evidenciaram que houve mobilização dos afetos e dos conceitos da abordagem psicossocial. As situações práticas apresentadas tiveram, como foco, as relações interpessoais e os dilemas próprios da condição humana. A incompletude na internalização do processo, permite considerar que as participantes não acomodaram o novo referencial aos esquemas de pensamento e de ação, projetando iniciativas ainda incipientes de reformulações, o que requer novos investimentos.

A análise desse resultado nos remete ao caráter inovador da abordagem, o que, efetivamente, pressupõe maior tempo e mais investimentos no sentido do reforço e do acompanhamento do grupo. Mais do que sensibilizar o grupo e acrescentar conteúdos, cabe ampliar situações de aprendizagem capazes de mobilizar conceitos e práticas da AD, reforçando princípios e expressões de raciocínio psicossocial, para o desenvolvimento de uma competência relacional imprescindível à aplicação do referencial da abordagem psicossocial $^{(7)}$ na AD.

Há necessidade, portanto, de maior e melhor preparo dos profissionais que atuam na $\mathrm{AD}$, para identificar as demandas e saber propor intervenções conjuntamente acordadas entre esses e o indivíduo e família. A abordagem psicossocial mostra ser uma estratégia a ser considerada, tanto para as instituições formadoras de profissionais de saúde, quanto para as empresas de AD e para as cooperativas de saúde, em grande parte responsáveis pelo fornecimento de recursos humanos para atuar no domicílio. Assim, poderá ser dada uma nova dimensão de cuidar no domicílio, o que possibilitará uma ação mais resolutiva e com maior satisfação para os envolvidos.

\section{REFERÊNCIAS}

1. Püschel VAA. Panorama da assistência domiciliar no município de São Paulo: caracterização dos serviços e da dinâmica de trabalho [relatório de pesquisa]. São Paulo: Escola de Enfermagem da Universidade de São Paulo; 2002.

2. Püschel VAA, Ide CAC. Assistência domiciliária no município de São Paulo: a infra-estrutura e o modelo de assistência [resumo]. In: $2^{\circ}$ Encontro Internacional de Pesquisa em Enfermagem; 2002, Out 28-31; Águas de Lindóia. Livro de resumos. São Paulo: EEUSP; 2002. p.126.

3. Püschel VAA. Abordagem construtivista no desenvolvimento de competências psicossociais para a assistência domiciliar [tese]. São Paulo: Escola de Enfermagem da Universidade de São Paulo; 2003.

4. Cruz ICF, Barros SRTP, Ferreira HC. Enfermagem em home care e sua inserção nos níveis de atenção à saúde: a experiência da Escola de Enfermagem da Universidade Federal Fluminense. Enferm Atual 2001; 1(4): 35-8.

5. Püschel VAA, Ide CAC, Chaves EC. Competências psicossociais para a assistência domiciliar. Rev Bras Enfermagem. 2005; 58(4):466-70.

6. Carretero M. Construtivismo e educação. Porto Alegre: Artes Médicas; 1997.

7. Püschel VAA, Ide CAC, Chaves EC. Instrumento para a abordagem psicossocial do indivíduo e da família na assistência domiciliar: condições de aplicabilidade. Acta Paul Enfermagem. 2005; 18(2):203-12. 